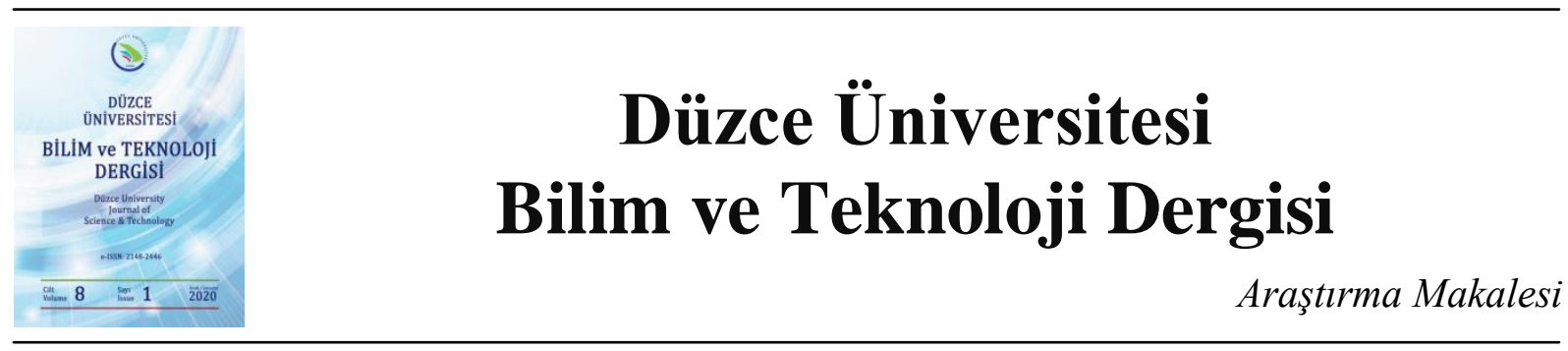

\section{Çay Endüstrisi Atık Küllerinin Beton Üretiminde Değerlendirilmesi}

\author{
(iD İlknur BEKEM KARA ${ }^{a, *}$ \\ ${ }^{a}$ İnşaat Bölümü, Borçka Acarlar MYO, Artvin Çoruh Üniversitesi, Artvin, TÜRKIYE \\ * Sorumlu yazartn e-posta adresi: ilknurbekem@artvin.edu.tr
}

DOI: 10.29130/dubited.567964

\begin{abstract}
ÖZET
Çay fabrikalarında, çay üretimi sırasında gerekli olan buhar temini için yakıt olarak kömür kullanılmaktadır. Buhar gereksinimindeki enerjinin sağlanması için kullanılan kömürün yanması ile tabanda cüruf atığı ve kuru tip toz siklon filtre sisteminde atık kül oluşmaktadır. Cüruf atığııın yollarda dolgu malzemesi olarak değerlendirildiği bilinmektedir. Ancak, filtre sisteminde biriken atı̆̆ın oldukça ince bir yapıya sahip olduğu ve aktif olarak değerlendirildiği bir kullanım alanının bulunmadığı tespit edilmiştir. Atıkların zararlı etkilerinin bertaraf edilmesi, depolama sorunlarının giderilmesi endüstrilerde önemli sorunların başında gelmektedir. İnsan sağlığına zararları bulunmayan endüstriyel atıkların beton üretiminde kullanılabilirliğinin değerlendirilmesi çevre ve depolama sorunlarını ortadan kaldıracağı gibi kısıtlı olan doğal kaynakların kullanımını da azaltacaktır.

$\mathrm{Bu}$ çalı̧̧mada çay fabrikası atık külünün beton üretiminde değerlendirilmesine yönelik olarak atık malzeme $\% 0$ (Referans), \%5, \%10 ve \%15 oranlarda çimentoya ağırlıkça ikame edilmiştir. Atık küllerin ikamesi ile hazırlanan taze betonların çökme miktarı ölçülerek kalıplara yerleştirilmiştir. Kül ikamesi ile üretilen beton numuneler 7, 28 ve 90 gün standart kür edilmişlerdir. Sertleşmiş beton numuneleri üzerinde fiziksel ve mekanik deneyler gerçekleştirilmiştir. Sonuç olarak, atık külün çalışmada kullanılan miktarlarda beton üretiminde çimento ikame malzemesi olarak değerlendirilebileceği belirlenmişsir.
\end{abstract}

Anahtar Kelimeler: Çay fabrikası, Endüstriyel atık, Kül, Çimento, Beton

\section{Evaluation of Tea Industrial Waste Ashes in Concrete Production}

\begin{abstract}
In tea factories, coal is used as fuel for the supply of steam which is required during tea production. Steam requirement with the combustion of coal used to provide energy slag waste at the bottom and dry type dust in cyclone filter system waste ash occur. It is known that slag waste is considered as filling material on the roads. However, it has been determined that the waste collected in the filter system has a very thin structure and is not used as an active area. Disposing of the harmful effects of wastes and eliminating the storage problems are the major problems in the industry. The assessment of the usability of industrial wastes that do not have any harm to human health in concrete production will eliminate environmental and storage problems and will reduce the use of limited natural resources.
\end{abstract}

In this study, waste material is used to evaluate the waste ash in the production of concrete, waste material is $0 \%$ (reference), 5\%,10\% and 15\% by weight to cement. The settling amount of fresh concrete prepared by substitution of waste ashes was measured and placed in molds. Concrete samples produced with ash substitution were standard cured 7, 28 and 90 days. Physical and mechanical tests were performed on hardened concrete samples. As a result, it was determined that waste ash can be considered as a substitute material in cement to be used in the production of concrete in the amounts used in the study. 


\section{GIRIS}

Beton, en yaygın kullanılan inşaat malzemesidir ve onu üretmek için çok büyük miktarda doğal kaynak gerekmektedir. Göreceli olarak son zamanlarda yaşanan hızlı endüstriyel gelişmelerin yanı sıra insanların yaşam standartlarının iyileştirilmesiyle, evsel ve endüstriyel atıkların hacmi artmakta ve bu atıkların çoğu geri dönüştürülmemektedir [1]. Endüstriyel atıkların geri dönüşüme kazandırılması insan sağlığı ve çevre kirliliğinin önlenmesi için büyük önem taşımaktadır [2]. Beton üretimi için gerekli olan malzemelerin yerine kısmen veya tamamen endüstriyel atık kullanımı son zamanlarda yoğun olarak araştırılmaktadır [1,3]. Atık geri dönüşümünün ana faydaları, çevre kirliliğinin azaltılması ve doğal kaynakların korunmasıdır. İnşaat endüstrisi için, hammadde kullanımında sürdürülebilirlik, beton oluşturan hammaddelerin sonlu olduğu göz önüne alındığında çok dikkat çekmektedir [4]. Ayrıca atık malzemelerin beton üretiminde kullanılması ile atıkların depolanma veya bertaraf edilmesi için harcanan maliyet ortadan kalkmakta ve daha az doğal kaynak tüketimi yapılmaktadır $[5,6]$.

Çay işleme fabrikaları, çay yapraklarını soldurmak ve kurutmak için kömür rezervlerinden faydalanmakta ve önemli miktarda atık kül ortaya çıkmaktadır. Çay Fabrikası atık külü, yanmamış karbon partiküllerinin, ağır metallerin ve kompleks organik bileşiklerin iyi bir oranını içeren çeşitli organik ve inorganik bileşiklerin kompleks bir karışımıdır [7]. Bununla birlikte, atık kül bileşenleri, toprak ve su kaynaklarını büyük ölçüde kirleten hem çözünür hem de çözünmeyen ağır metaller içermektedir [7]. Ayrıca uzun vadeli tarımsal uygulamalarda kullanımının toprak sağlığını etkileyebileceği ancak insan sağlığı risk analizi sonuçlarına göre ise, tüm çay fabrikası atık küllerinin metal konsantrasyonlarının, potansiyel kanser risk seviyelerinin altında olduğu belirtilmiştir [8].

Uçucu kül, yüksek firın cürufu, silis dumanı ve pirinç kabuğu külü gibi atık ürünler sektörde ağırlıklı olarak kullanılmaktadır $[3,9,10]$.Uçucu kül ve silis dumanı ile yapılan bir çalışmada 90 . günde uçucu külün \%5, silis dumanının ise \%15 oranında çimentoya ikamesi ile kontrol karışımdan daha yüksek bir basınç dayanımı elde edilmiştir[11]. Başka bir çalışmada ise3 tip farklı pirinç kabuğu külü (Kül-1, Kül-2 ve Kül-3) \%10 ve \%20 oranlarda çimento yerine beton üretiminde kullanılmıştır. Kül-1 ve Kül2 tipi pirinç kabuğu külleri basınç dayanımını azaltırken Kül-3 tipi pirinç kabuğu külünün basınç dayanımını arttırdığı belirtilmiştir[12].

Yapılan çalışmalar neticesinde tehlikeli olmayan atık malzemeler, sürdürülebilir bir yapı malzemesi üretmek için kısmen kullanılabilmektedir [13]. Ayrıca doğal kaynakların korunması ve zararlı baca gazı salınımlarının kısıtlanması gibi etkenler çimento-beton üretiminde endüstriyel atıkların değerlendirilmesinin önemli olduğunu göstermektedir [14]. Beton üretimi için tüketilen enerjinin \%94'ü çimento üretiminden kaynaklanmaktadır. Bu bağlamda beton üretimi için gerekli malzemelerin yerine endüstriyel atıkların değerlendirilerek geri dönüşüme kazandırılması gerekmektedir. Atık malzemelerin geri dönüşüme kazandırılması ile hem çevreye olan zararlı etkileri hem de depolama ve kaynak tüketim maliyetleri azaltılmış olacaktır. Bu çalışma ile atık kül çimentoda ağırlıkça $\% 0, \% 5$, $\% 10$ ve $\% 15$ oranlarda ikame malzemesi olarak kullanılmıştır. Yapılan ikame ile taze betonların işlenebilirliği ve sertleşmiş betonların dayanımları üzerinde atık külün etkileri incelenmiştir.

\section{MATERYAL VE METOD}

\section{A. MATERYAL}

Çalışmada beton üretimi için CEM I $42.5 \mathrm{R}$ çimentosu, çay fabrikası atık külü, kırmataş agrega, şebeke suyu ve süper akışkanlaştırıcı katkı malzemeleri kullanılmıştır. CEM I $42.5 \mathrm{R}$ çimentosuna ait kimyasal, fiziksel ve basınç dayanımı özellikleri Tablo 1'de verilmiştir. 
Tablo 1. CEM I 42.5 R çimentosuna ait teknik özellikler

\begin{tabular}{|c|c|c|c|c|c|}
\hline Analiz & Oksit & Değer & Analiz & Deneyler & Değer \\
\hline \multirow{9}{*}{ 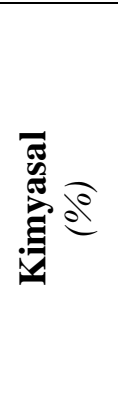 } & $\mathrm{CaO}$ & 62.64 & \multirow{5}{*}{ 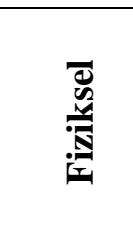 } & Özgül vüzey $\left(\mathrm{cm}^{2} / \mathrm{g}\right)$ & 3269 \\
\hline & $\mathrm{Al}_{2} \mathrm{O}_{3}$ & 4.56 & & Hacim genleşmesi $(\mathrm{mm})$ & 2.0 \\
\hline & $\mathrm{Fe}_{2} \mathrm{O}_{3}$ & 3.36 & & Yoğunluk $\left(\mathrm{g} / \mathrm{cm}^{3}\right)$ & 3.12 \\
\hline & $\mathrm{SiO}_{2}$ & 19.05 & & Priz başlama süresi $(d k)$. & 150 \\
\hline & $\mathrm{SO}_{3}$ & 2.88 & & Priz bitiş süresi $(d k)$. & 210 \\
\hline & $\mathrm{MgO}$ & 2.98 & \multirow{4}{*}{ 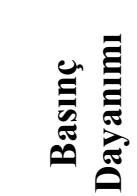 } & Gün & Değer \\
\hline & $\mathrm{Na}_{2} \mathrm{O}$ & 0.15 & & 2. gün $(M P a)$ & 32.5 \\
\hline & Kızdirma kayb1 & 3.02 & & 7. gün $(M P a)$ & 43.4 \\
\hline & Çözünmeyen kalınt1 & 0.30 & & 28. gün $(M P a)$ & 53.6 \\
\hline
\end{tabular}

Beton karışımlarında kullanılan agregaların tane yoğunlukları ve su emme değerleri TS EN 1097-6 standardında belirtilen şartlara uygun olarak belirlenmiştir [15]. Agrega tane boyutları 0-5, 0-5 (yıkanmış), 5-12 ve 12-25 olup yoğunlukları sırasıyla 2.60, 2.63, $2.70 \mathrm{ve} 2.72 \mathrm{~g} / \mathrm{cm}^{3}$ ' tür. Agregaların su emmeleri ise \%3.00, \%2.30, \% 1.65 ve \%1.20 olarak hesaplanmıştır [15]. Ayrıca agregaların tane dağılımı belirlenmiş olup beton üretimine uygun olduğu görülmüştür [16, 17].SA katkıs1 ise karışımlarda çimento ağırlığının \%1'i olarak kullanılmıştır.

Çalışmada kullanılan çay fabrikası atık külü Artvin ili Borçka ilçesinde faaliyet gösteren Muratlı çay fabrikasından temin edilmiştir. Depolama ortamı açık olduğu için temin edilen kül $100 \pm 5{ }^{\circ} \mathrm{C}^{\prime} \mathrm{de}$ kurutulmuş ardından $0.125 \mathrm{~mm}$ elekten elenmiş ve elek altında kalan malzeme çimentoda ikame malzemesi olarak kullanılmıştır. Taramalı elektron mikroskop görüntülerinde külün düzensiz küresel şekillerden oluştuğu ve yanmamış karbonlar içerdiği görülmektedir. Küle ait taramalı elektron mikroskobu görüntüleri Şekil 1'te verilmiştir.

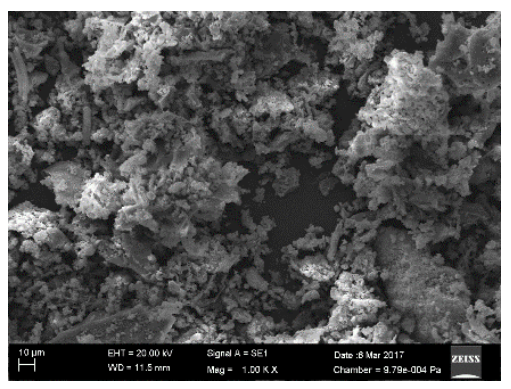

(a)

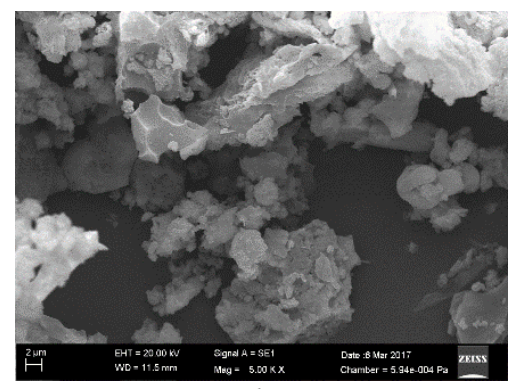

(b)

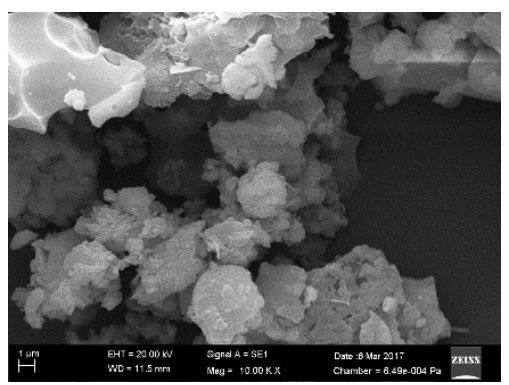

(c)

Şekil 1. Çay fabrikası atık külüne ait taramalı elektron mikroskobu görüntüleri: (a) x1000 (b) x5000 (c) x10000

Yoğunluğu $0.99 \mathrm{~g} / \mathrm{cm}^{3}$ ve özgül yüzeyi $3745 \mathrm{~cm}^{2} / \mathrm{g}$ [18] olan küle ait kimyasal analiz sonuçları ise Tablo 2'de verilmiştir.

Tablo 2. Çay fabrikası atık külüne ait kimyasal analiz sonuçları

\begin{tabular}{ccccccccc}
\hline $\begin{array}{c}\text { Kimyasal } \\
\text { Bileşen } \\
\text { Değer } \\
(\%)\end{array}$ & $\mathrm{CaO}$ & $\mathrm{Al}_{2} \mathrm{O}_{3}$ & $\mathrm{Fe}_{2} \mathrm{O}_{3}$ & $\mathrm{SiO}_{2}$ & $\mathbf{S O}_{3}$ & $\mathrm{MgO}$ & $\begin{array}{c}\text { Kuzdırma } \\
\text { Kaybı }\end{array}$ & $\mathrm{SiO}_{2}+\mathrm{Fe}_{2} \mathrm{O}_{3}+\mathbf{A l}_{2} \mathrm{O}_{3}$ \\
\hline
\end{tabular}

Külün kimyasal içeriğinde $\mathrm{SiO}_{2}+\mathrm{Fe}_{2} \mathrm{O}_{3}+\mathrm{Al}_{2} \mathrm{O}_{3}$ toplamının \%70'den ve özgül yüzeyinin ise 3000 $\mathrm{cm}^{2} / \mathrm{g}$ yüksek olduğu görülmektedir. Kül ikameli beton tasarım ve üretim aşamasından önce külün puzolanik aktivite deneyi yapılmıştır [19]. Kül ile priz süresinin ve su ihtiyacının arttırdığı görülmüş olup; referans (\%100 CEM I 42.5 R) ve kül (\%75 CEM I $42.5 \mathrm{R}+\% 25$ Kül) içeren harç numuneler hazırlanmıştır. 28. gün dayanımlar belirlenmiş ve külün aktivite indeksi \%84.18 olarak hesaplanmıştır. 
28. gün puzolanik aktivite indeksinin en az $\% 75$ olması gerektiği ve dolayısıyla çay fabrikası atık külünün puzolanik özellikte olduğu kanısına varılmıştır.

\section{B. METOD}

Çimentoya kül ikamesinin \%0 (Ref.), \%5, \%10 ve \%15 oranlarında kullanılması ile beton tasarım ve üretimi gerçekleştirilmiştir. Beton karışımları TS 802 ve TS EN 206-1 standartlarına uygun olarak gerçekleştirilmiştir $[20,21] . \% 0, \% 5, \% 10$ ve $\% 15$ oranlarda kül çimentoya ikame edilmesiyle C20/25 sınıfı toplamda dört farklı beton üretilmiş olup üretilen beton numuneler sırasıly Ref, $5 \mathrm{~K}, 10 \mathrm{~K}$ ve $15 \mathrm{~K}$ olarak etiketlenmiştir. Beton karışımına giren malzeme miktarları ağırlık olarak Tablo 3 'te verilmiştir.

Tablo 3. Beton karışım oranları (ağırlıkça)

\begin{tabular}{|c|c|c|c|c|}
\hline $\begin{array}{c}\text { Etiketleme } \\
\text { İkame Oranları }\end{array}$ & $\begin{array}{l}\text { Ref. } \\
(\% 0)\end{array}$ & $\begin{array}{l}\mathbf{5 K} \\
(\% 5) \\
\end{array}$ & $\begin{array}{l}\mathbf{1 0 K} \\
(\% 10)\end{array}$ & $\begin{array}{l}\mathbf{1 5 K} \\
(\% 15) \\
\end{array}$ \\
\hline $\begin{array}{l}\text { Çimento } \\
(\mathrm{kg})\end{array}$ & 300 & 285 & 270 & 255 \\
\hline $\begin{array}{l}\text { Kül } \\
(\mathrm{kg})\end{array}$ & 0 & 15 & 30 & 45 \\
\hline $\begin{array}{l}\text { Su } \\
(l t)\end{array}$ & 180 & 180 & 180 & 180 \\
\hline $\begin{array}{c}\text { Süper akışkanlaştırıcı } \\
(l t)\end{array}$ & 3 & 3 & 3 & 3 \\
\hline $\begin{array}{c}\text { 0-5 kırma kum } \\
(\mathrm{kg})\end{array}$ & 344 & 344 & 344 & 344 \\
\hline 0-5 kırma kum (yıkanmış) & 694 & 694 & 694 & 694 \\
\hline $\begin{array}{l}\text { 5-12 kırmataş } \\
(\mathrm{kg})\end{array}$ & 417 & 417 & 417 & 417 \\
\hline $\begin{array}{c}\text { 12-25 kırmataş } \\
(\mathrm{kg})\end{array}$ & 500 & 500 & 500 & 500 \\
\hline
\end{tabular}

Bütün beton karışımları laboratuvar tipi beton mikserinde standartlara uygun olarak karıştırılmıştır [22].Üretimi yapılan taze betonların çökme miktarları ölçülmüş ve farklı boyuttaki küp kalıplara yerleştirilmiştir [23]. Schmidt çekici [24], ultrases geçiş hızı [25], su emme [26] ve basınç dayanımı [27]için 150x150x150 mm; aşınma kaybının [28] belirlenmesi için ise 70.7x70.7x70.7 mm küp numuneler kullanılmıştır.7, 28 ve 90 gün kür havuzunda bekleyen beton numuneler üzerinde sertleşmiş beton deneyleri gerçekleştirilerek elde edilen sonuçlar karşılaştırılmıştır.

\section{BULGULAR VE DEĞERLENDİRME}

Farklı oranlarda kül ikamesi ile hazırlanan beton türleri üzerinde taze betonların işlenebilirliğinin belirlenmesi için çökme miktarı deneyi standartlara uygun olarak gerçekleştirilmiş ve elde edilen değerler Şekil 2'de verilmiştir. Standartta belirtilen çökme sınıflarına göre çökme miktarı ölçülen referans beton türünün çökme sınıfı S3 $(10-15 \mathrm{~cm})$ olarak belirlenmiştir. $\% 5, \% 10$ ve \%15 kül ikameleri ile çökme sınıflarının ise sırasıyla S3 $(10-15 \mathrm{~cm})$, S2 $(5-9 \mathrm{~cm})$ ile S1 $(1-4 \mathrm{~cm})$ olduğu tespit edilmiştir [21, 23]. Taze betonun işlenebilirlik ölçütü olarak kabul edilen çökme miktarının kül ikamesinin artması ile düştüğü dolayısıyla işlenebilirliğin azaldığ1 görülmüştür. Kül yoğunluğunun çimentodan düşük olması ile hacimce çimentodan daha fazla kül karışımlara girmiştir. İşlenebilirliğin azalması, ince malzeme hacminin artması ve dolayısıyla ise su ihtiyacının artışına sebep olması ile açıklanabilir bir durumdur. 


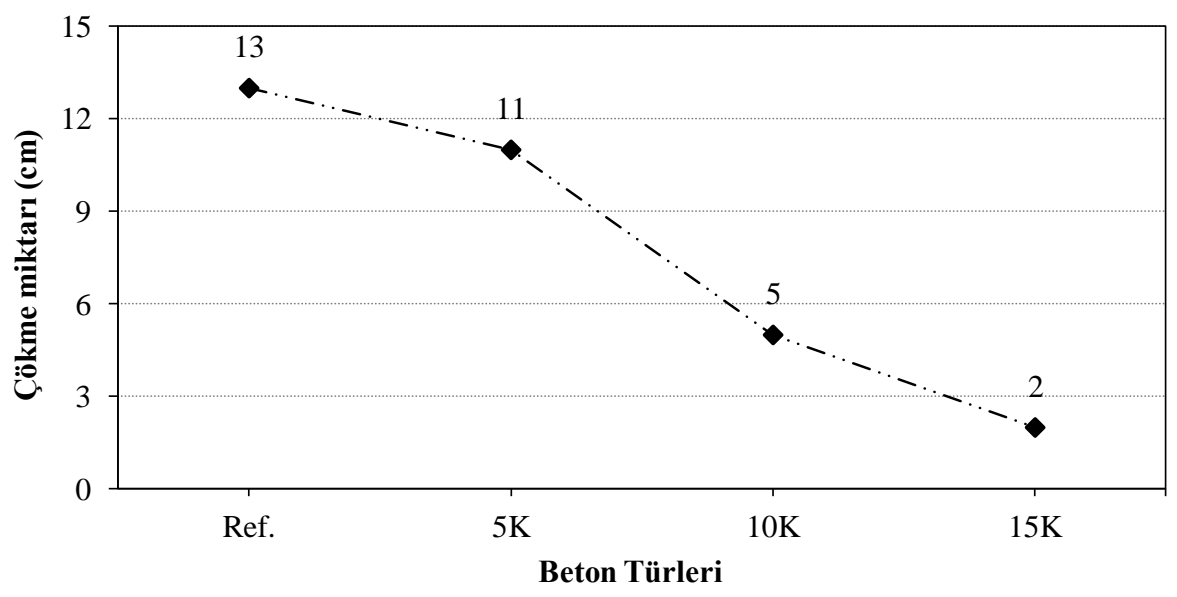

Şekil 2. Çökme miktarl değerleri

Beton türleri üzerinde kapiler su emme deneyi gerçekleştirilmiş ve numunelere ait kapiler su emme katsayıları hesaplanmıştır. 7, 28 ve 90 günlerde hesaplanan kapiler su emme katsayıları Şekil 3'de gösterilmiştir. Referans beton türünün kapiler su emme katsayısı 7 günlük ölçümlerde kül ikameli beton türlerinden daha yüksek sonuçlanmıştır. Diğer yaşlarda bütün beton türlerinde kapiler su emme katsayısı zamanla azalmıştır ve en düşük kapiler su emme katsayısı 10K ve $15 \mathrm{~K}$ beton türleri ile elde edilmiştir.

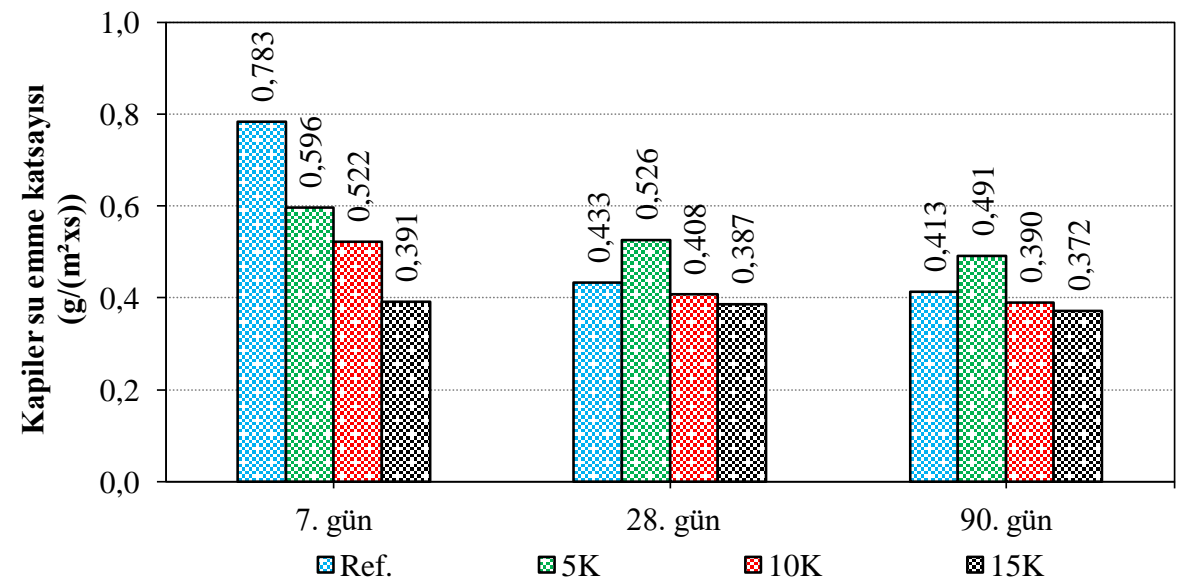

Şekil 3. Kapiler su emme katsayısı değerleri

Beton numunelerin kırılması, betonun dayanımını değerlendirilmesi için tahribatlı bir testtir. Schmidt çekici ve ultrases geçiş hızı testi gibi tahribatsız yöntemler yapılara zarar vermez ve yapıların mevcut durumunun değerlendirilmesine olanak sağlamaktadırlar [29]. Beton numunelerin basınç dayanımı belirlenmeden önce Schmidt çekici ve ultrases geçiş hızı testleri ile ölçümleri yapılmıştır.

Schmidt çekici testi ile belirlenen geri tepme sayıları cihaz üzerinde bulunan grafik ile yaklaşık basınç dayanımına dönüştürülmüştür. Elde edilen yaklaşık basınç dayanımı değerleri Şekil 4'te görülmektedir. Schmidt çekicinin temel olarak bir yüzey sertliği test cihazıdır [30]. 7 günlük ölçümler incelendiğinde kül ikamesi ile beton numunelerin yüzeylerinin sertleştiği ve referans beton türüne göre nispeten daha sert bir yüzey oluşturduğu söylenebilir. Ancak betonun yaşı arttıkça referans beton türünün diğer beton türlerinden daha yüksek bir yüzey sertliğine sahip olduğu görülmüştür. 


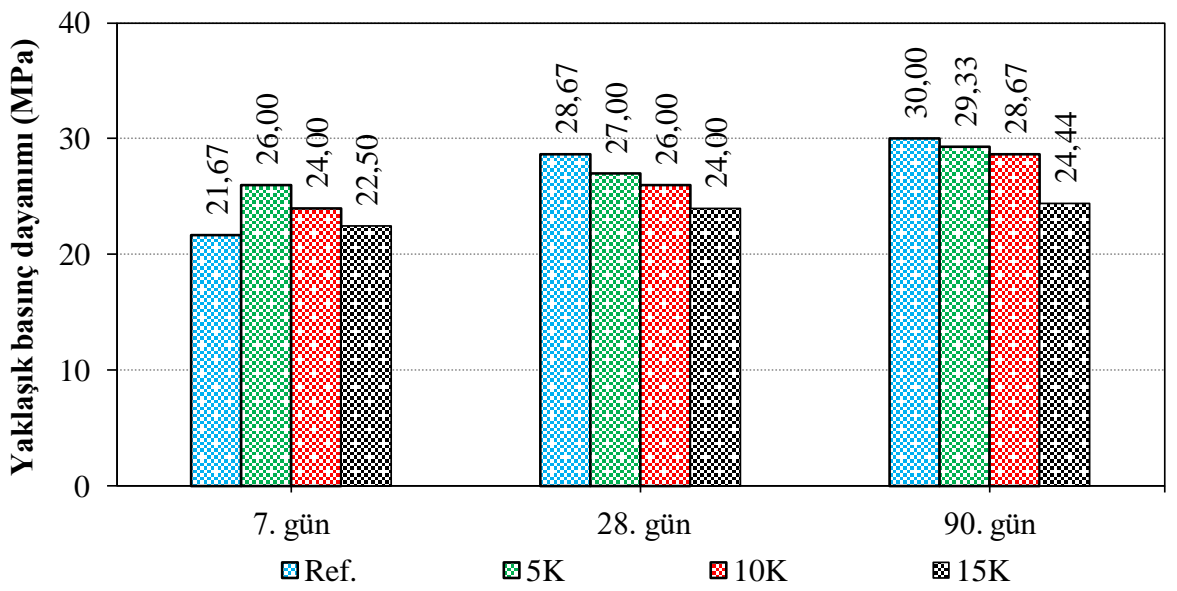

Şekil 4. Schmidt çekici ile elde edilen yaklaşık basınç dayanımı değerleri

Ref, $5 \mathrm{~K}, 10 \mathrm{~K}$ ve $15 \mathrm{~K}$ beton türlerinde ölçülen ultrases geçiş hızları Şekil 5'de sunulmuştur. Literatürde ultrases geçiş hızının erken yaşta çok hızlı arttığını ve daha sonra yavaşladığı belirtilmektedir [31]. Beton numunelerin ultrases geçiş hızı ölçümleri incelendiğinde, literatür ile benzerlik göstermektedir. Kür süresinin artması ile bütün beton türlerinde ultrases geçiş hız değeri artmıştır. 7 günlük ultrases geçiş hızı ölçümlerinde en yüksek değer $5 \mathrm{~K}, 28$ ve 90 günlerde ise referans beton türü ile elde edilmiştir. Betonun kalitesi ile ultrases geçiş hızı değerleri ilişkilendirilmektedir. Ultrases geçiş hızı değerinin $3.5 \mathrm{~km} / \mathrm{s}$ ile $4.5 \mathrm{~km} / \mathrm{s}$ aralığında ise beton kalitesi "iyi", $4.5 \mathrm{~km} / \mathrm{s}$ 'den yüksek olmasında ise beton kalitesi "mükemmel" olarak nitelendirilmektedir [32]. Ultrases geçiş hızı ile beton kalitesi ilişkisine göre; 7 günün sonunda bütün betonların kalitesi "iyi" olarak sonuçlanmıştır. 28 ve 90 günlerde ise referans ve $5 \mathrm{~K}$ beton türleri "mükemmel", diğer beton numunelerin kalitesinin ise "iyi" olduğu görülmüştür.

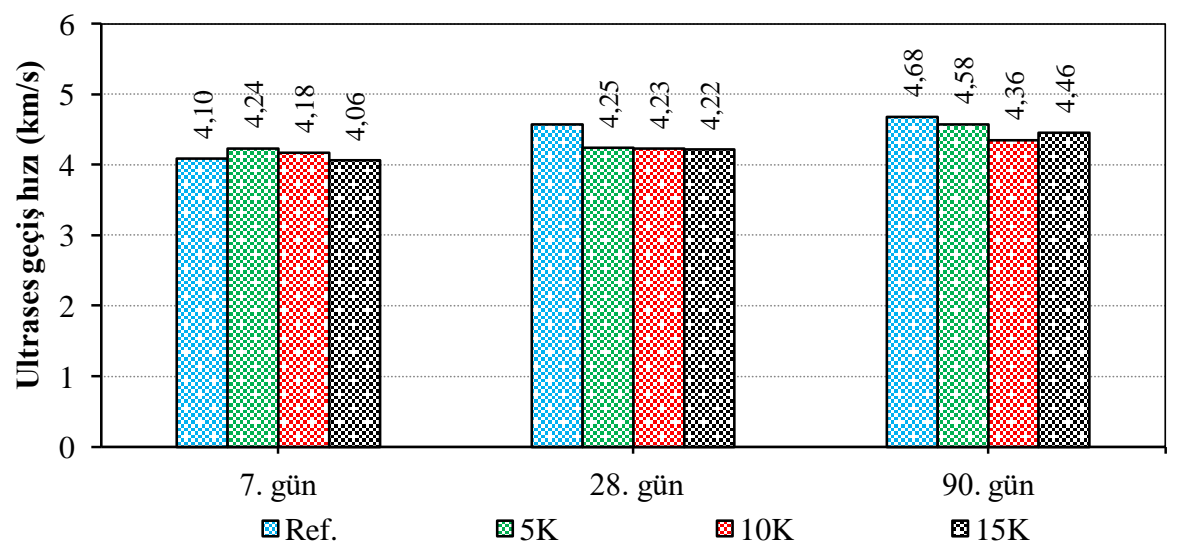

Şekil 5. Ultrases geçiş hızı değerleri

Farklı oranlarda kül ikamesi ile üretimi yapılan beton numunelerin basınç dayanımları 7, 28 ve 90 . günlerde belirlenmiştir (Şekil 6). Kül ikamesinin 7. gün basınç dayanımını referans beton örneğine göre arttırdığı görülmüştür. Diğer yaşlarda ise kül ikameli beton türleri referans beton türünden düşük basınç dayanımları ile sonuçlanmıştır. Kül ikameli $5 \mathrm{~K}, 10 \mathrm{~K}$ ve $15 \mathrm{~K}$ beton türlerinin basınç dayanımları referans ile kıyaslandığında; 7. gün sırasıyla \%19.70, \%17.19 ve \%7.07 dayanım artışı sağlamıştır. 28. gün $\% 7.47, \% 16.75$ ve $\% 20.21$ dayanım kaybı meydana gelmiştir. 90 . gün basınç dayanımı sonuçlarına göre ise $\% 4.43, \% 5.31$ ve $\% 5.51$ dayanım kaybı olduğu belirlenmiştir. Kül ikamesi ile başlangıçta dayanım artışı ileriki yaşlarda ise referans beton türüne göre dayanım kaybı görülmüştür. Ancak dayanım kaybı betonların yaşının artmasıyla azalmış olduğu ve referans örneğe yakın sonuçlar elde edildiği görülmektedir. Betonların yaşının artmasıyla kül ikameli betonların basınç 
dayanımlarının referansa daha yakın sonuçlanma ihtimali yüksektir. Kül ile yapılacak sonraki çalışmalarda bunun göz önünde bulundurulmasının önemli olduğu düşünülmektedir.

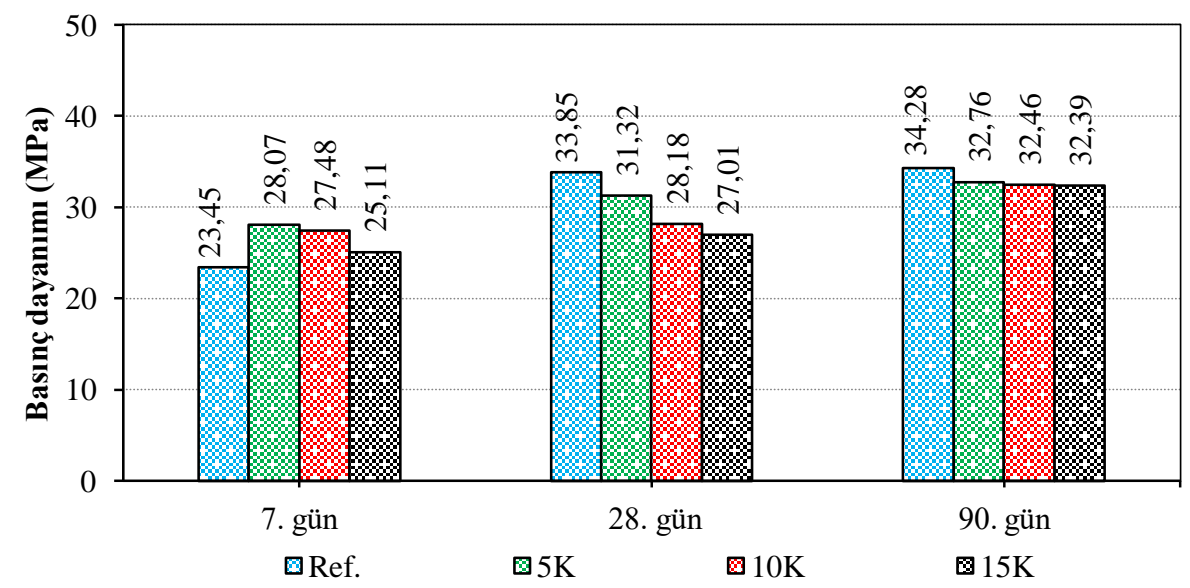

Şekil 6. Basınç dayanımı değerleri

Beton türlerini üzerinde yüzey aşınma deneyi gerçekleştirilmiş olup hesaplanan hacimsel aşınma miktarları Şekil 7' de verilmiştir. Tüm yaşlarda en iyi aşınma dayanımı $5 \mathrm{~K}$ beton türünde görülmüştür. $\% 5$ kül ikamesi referans betona göre aşınma kaybını 7. gün $\% 6.29,28$. gün $\% 10.49,90$. gün ise \%20.48 azaltmıştır. Kül ikame oranı arttıkça aşınma miktarlarının arttığı belirlenmiştir. Aşınma miktarının artması veya azalması gerçeği, mineral tozun cinsi ve karışımdaki konsantrasyonuna bağlı olmakla birlikte yüzeydeki gözenekleri dolduran mineral tozların kullanımı ile aşınma miktarını azaltabilmektedir [33]. 90. Günde tüm ikame oranlarında beton türlerine ait aşınma kayıplarının referans beton türünden daha az olduğu tespit edilmiştir.

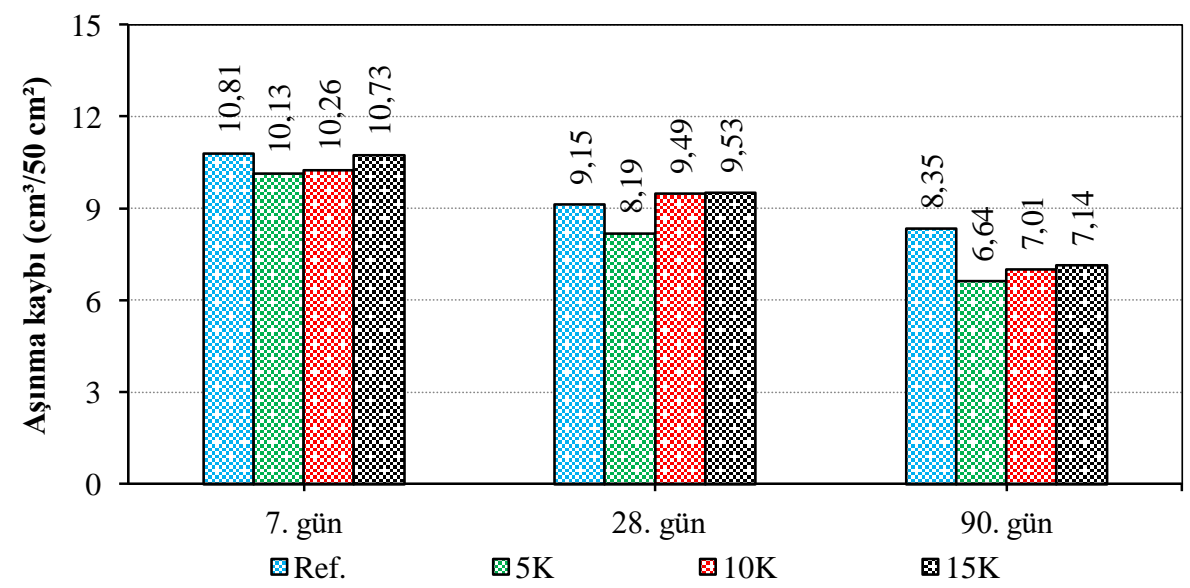

Şekil 7. Aşınma kaybu değerleri

\section{IV.SONUC}

Çay endüstrisi atık külünün kullanılabilirliği ve beton üzerindeki etkilerinin incelendiği bu çalışmada çimentoya ağırlıķa $\% 5, \% 10$ ve $\% 15$ oranlarında kül ikame edilmesi ile üretilen betonlardan elde edilen sonuçlar aşağıda verilmiştir.

- Kül ikamesi arttıkça, taze beton numunelerinin işlenebilirliğinin azaldığı ve su ihtiyacının arttığı belirlenmiştir. 
- Beton numunelerinin kapilarite katsayıları incelendiğinde kül ikame oranının artması ile kapilarite katsayısının azaldığı ve en yüksek kapilarite katsayısının $5 \mathrm{~K}$, en düşük kapilarite katsayısının ise $15 \mathrm{~K}$ beton türüne ait olduğu tespit edilmiştir.

- Schmidt çekici, ultrases geçiş hızı ve basınç dayanımı testlerine ait değerler incelendiğinde elde edilen sonuçların benzer olduğu görülmüştür. Yapılan bu deneyler sonucunda kül ikamesi ile erken yaşlarda (7. gün) $5 \mathrm{~K}, 10 \mathrm{~K}$ ve $15 \mathrm{~K}$ beton türlerine ait Schmidt çekici, ultrases geçiş hızı ve basınç dayanımları değerlerinin referans beton türünden yüksek olduğu belirlenmiştir. Ancak diğer yaşlarda (28 ve 90. gün) en yüksek değerleri referans beton türü sağlamıştır. Kül ikamesinin betonun erken dayanımını arttırdığı, ileriki yaşlarda ise referans beton türü ile yakın sonuçlar elde edildiği söylenebilir.

- Kül ikamesi ile üretilen beton numunelerinin basınç dayanım sonuçları ileriki yaşlarda dayanım kaybının önemli oranlarda olmadığı göstermiştir. Referans örneğe göre kül ikamesi 90. günün sonunda ortalama $\% 5.1$ daha düşük dayanım elde edilmesine neden olmuştur. Ancak düşük dayanım kaybına rağmen bütün beton türlerinin C20/25 tasarımındaki hedef basınç dayanımını sağladığı görülmüştür.

- Kül ikamesinin bütün ikame oranları betonların aşınma miktarını referans betona göre tüm yaşlarda azaltmıştır. Külün aşınma kaybına olan olumlu etkisi betonun ileri yaşlarında oldukça belirgindir. Üretilen beton türleri içinde en az aşınma miktarı $5 \mathrm{~K}$ beton türünde elde edilmiştir.

Sonuç olarak çalışma kapsamında \%15'e kadar kül ikamesinin betonlarda kullanılabileceği kanısına varılmıştır. Atıkların değerlendirilmesi amacı ile bu atığın özellikle çay fabrikalarının olduğu bölgelerde betonda kullanılması nakliye masrafları düşünüldüğünde daha uygun olacaktır. Ayrıca, aşınma dayanımının kül ikamesi ile artışı göz önüne alındığında bu atığın beton kaplamalarda değerlendirilmesinin faydalı olacağı düşünülmektedir. Bundan sonraki çalışmalarda külün betonun durabilite özelliklerine etkisi ve agrega yerine beton içerisinde kullanılabilirliğinin araştırılması önerilmektedir.

TEȘEKKÜR: $\mathrm{Bu}$ çalışmaArtvin ÇoruhÜniversitesi Bilimsel Araştırma Projeleri tarafindan desteklenmiştir (Proje no: 2016.F94.02.01).

\section{KAYNAKLAR}

[1] I. S. Kim, S. Y. Choi and E. I. Yang, "Evaluation of durability of concrete substituted heavyweight waste glass as fine aggregate," Construction and Building Materials, vol. 184, pp. 269$277,2018$.

[2] H. Mohammadhosseini and M. M. Tahir, "Durability performance of concrete incorporating waste metalized plastic fibres and palm oil fuel ash," Construction and Building Materials, vol. 180, pp. 92-102, 2018.

[3] M. C. G. Juenger and R. Siddique, "Recent advances in understanding the role of supplementary cementitious materials in concrete," Cement and Concrete Research, vol. 78, pp. 71$80,2015$.

[4] O. Onuaguluchi and D. K. Panesar, "Hardened properties of concrete mixtures containing precoated crumb rubber and silica füme," Journal of Cleaner Production, vol. 82, pp. 125-131, 2018.

[5] S. Yazıcıoğlu ve C. Kara, C., "Betonda atık mermer tozu kullanımının karbonatlaşmaya etkisi," Politeknik Dergisi, c. 20, s. 2, ss. 369-376, 2017.

[6] C. Kara, "Usability of Tea waste in concrete as natural fiber," Journal of Natural Hazards and Environment, vol. 4, no. 2, pp. 156-165, 2018. 
[7] L. Goswami, S. Sarkar, S. Mukherjee, S. Das, S. Barman, P. Raul and S. S. Bhattacharya, "Vermicomposting of tea factory coal ash: metal accumulation and metallothionein response in eisenia fetida (Savigny) and lampito mauritii (Kinberg)," Bioresource Technology, vol. 166, pp. 96-102, 2014.

[8] L. Goswami, P. Raul, B.Sahariah, P. Bhattacharyya and S.S. Bhattacharya, "Characterization and risk evaluation of Tea Industry Coal Ash for environmental suitability," Clean Soil Air Water, vol. 42, pp. 1470-1476, 2014.

[9] G. R. De Sensale, "Strength development of concrete with rice-husk ash," Cement and Concrete Composites, vol. 28, no. 2, pp. 158-160, 2006.

[10] R. Siddique, "Utilization of silica fume in concrete: Review of hardened properties," Resources, Conservation and Recycling, vol. 55, no. 11, pp. 923-932, 2011.

[11] D. Hatungimana, C. Taş̧öprü, M. İçhedef, M. M. Saç and Ş. Yazıcı, "Compressive strength, water absorption, water sorptivity and surface radon exhalation rate of silica fume and fly ash based mortar," Journal of Building Engineering, vol. 23, pp. 369-376, 2019.

[12] M. B. Ahsan and Z. Hossain, "Supplemental use of rice husk ash (RHA) as a cementitious material in concrete industry," Construction and Building Materials, vol. 178, pp. 1-9, 2018.

[13] V. S. Devi, "Durability properties of multiple blended concrete," Construction and Building Materials, vol. 179, pp. 649-660, 2018.

[14] İ. Bekem, A. B. Gültekin ve Ç. B. Dikmen, "Yap1 ürünlerinin hizmet ömrü açısından irdelenmesi: Betonarme örneği," 5. Uluslararası Illeri Teknolojiler Sempozyumu (IATS'09), Karabük, Türkiye, 2009, ss.2155-2160.

[15] Agregaların mekanik ve fiziksel özellikleri için deneyler-bölüm 6: tane yoğunluğunun ve su emme oranının tayini, Türk Standartları Enstitüsü TS EN 1097-6, 2013.

[16] Beton agregalarl, Türk Standartları Enstitüsü TS 706 EN 12620+A1, 2009.

[17] Agregaların geometrik özellikleri için deneyler-bölüm 1: tane büyüklüğü dağıllmı tayini-eleme metodu, Türk Standartları Enstitüsü TS EN 933-1:2012(EN), 2012.

[18] Çimento deney yöntemleri - bölüm 6: incelik tayini, Türk Standartları Enstitüsü TS EN 196-6, 2010.

[19] Uçucu kül - betonda kullanılan bölüm 1: tarif, özellikler ve uygunluk kriterleri, Türk Standartlar1 Enstitüsü TS EN 450-1, 2013.

[20] Beton karışım tasarımı hesap esasları, Türk Standartları Enstitüsü TS 802, 2016.

[21] Beton - özellik, performans, imalat ve uygunluk, Türk Standartları Enstitüsü TS EN 206:2013+A1, 2017.

[22] Beton yapım, döküm ve bakım kuralları (normal hava koşullarında), Türk Standartları Enstitüsü TS EN 1247, 2018.

[23] Beton - taze beton deneyleri - bölüm 2: çökme (slump) deneyi, Türk Standartları Enstitüsü TS EN 12350-2, 2010.

[24] Yapılarda beton deneyleri - bölüm 2: tahribatsı muayene- geri sıçrama saylsının belirlenmesi, Türk Standartları Enstitüsü TS EN 12504-2, 2013. 
[25] Concrete - standard test method for pulse velocity through concrete, United States ASTM C 597-83, 2009.

[26] Kagir birimler - deney yöntemleri - bölüm 11: betondan, gaz betondan, yapay ve doğal taştan yapılmış kagir birimlerde kapiler su emme ve kil kagir birimlerde ilk su emme hızının tayini, Türk Standartlar1 Enstitüsü TS EN 772-11, 2011.

[27] Beton - sertleşmiş beton deneyleri - bölüm 3: deney numunelerinin basınç dayanımının tayini, Türk Standartlar1 Enstitüsü TS EN 12390-3, 2010.

[28] Şap malzemeleri - deney yöntemleri - bölüm 3: aşınma direncinin tayini - böhme deneyi, Türk Standartlar1 Enstitüsü TS EN 13892-3, 2015.

[29] J. Malek and M. Kaouther, M.,"Destructive and non-destructive testing of concrete structures," Jordan Journal of Civil Engineering, vol. 8, no. 4, pp. 432-441, 2014.

[30] W. H. J. Tchamdjou, T.Cherradi, M. L. Abidi and L. A. Pereira-de-Oliveira, "Mechanical properties of lightweight aggregates concrete made with cameroonian volcanic scoria: Destructive and non-destructive characterization," Journal of Building Engineering, vol. 16, pp. 134-145, 2018.

[31] M. Benaicha, O.Jalbaud,A. H.Alaoui and Y. Burtschell, "Correlation between the mechanical behavior and the ultrasonic velocity of fiber-reinforced concrete," Construction and Building Materials, vol. 101, pp. 702-709, 2015.

[32] H.Y. Qasrawi, "Concrete strength by combined nondestructive methods simply and reliably predicted," Cement and Concrete Research, vol. 30, no.5, pp. 739-746, 2000.

[33] M. Popek, Ł. Sadowski and J. Szymanowski, "Abrasion resistance of concrete containing selected mineral powders,” Procedia Engineering, vol. 153, pp. 617-622, 2016. 